\title{
RESEARCH
}

Open Access

\section{4-Ethylguaiacol modulates neuroinflammation and Th1/Th17 differentiation to ameliorate disease severity in experimental autoimmune encephalomyelitis}

Wen-Tsan Weng ${ }^{1}$, Ping-Chang Kuo ${ }^{1}$, Dennis A. Brown², Barbara A. Scofield ${ }^{1}$, Destin Furnas ${ }^{1}$, Hallel C. Paraiso ${ }^{3}$, Pei-Yu Wang ${ }^{4}$, I-Chen $\mathrm{Yu}^{3}$ and Jui-Hung Yen ${ }^{1 *}$ (D)

\begin{abstract}
Background: Multiple sclerosis (MS) is a progressive autoimmune disease characterized by the accumulation of pathogenic inflammatory immune cells in the central nervous system (CNS) that subsequently causes focal inflammation, demyelination, axonal injury, and neuronal damage. Experimental autoimmune encephalomyelitis (EAE) is a well-established murine model that mimics the key features of MS. Presently, the dietary consumption of foods rich in phenols has been reported to offer numerous health benefits, including anti-inflammatory activity. One such compound, 4-ethylguaiacol (4-EG), found in various foods, is known to attenuate inflammatory immune responses. However, whether 4-EG exerts anti-inflammatory effects on modulating the CNS inflammatory immune responses remains unknown. Thus, in this study, we assessed the therapeutic effect of 4-EG in EAE using both chronic and relapsing-remitting animal models and investigated the immunomodulatory effects of 4-EG on neuroinflammation and Th1/Th17 differentiation in EAE.
\end{abstract}

Methods: Chronic C57BL/6 EAE and relapsing-remitting SJL/J EAE were induced followed by 4-EG treatment. The effects of 4-EG on disease progression, peripheral Th1/Th17 differentiation, CNS Th1/Th17 infiltration, microglia (MG) activation, and blood-brain barrier (BBB) disruption in EAE were evaluated. In addition, the expression of MMP9, MMP3, HO-1, and Nrf2 was assessed in the CNS of C57BL/6 EAE mice.

Results: Our results showed that 4-EG not only ameliorated disease severity in C57BL/6 chronic EAE but also mitigated disease progression in SJL/J relapsing-remitting EAE. Further investigations of the cellular and molecular mechanisms revealed that 4-EG suppressed MG activation, mitigated BBB disruption, repressed MMP3/MMP9 production, and inhibited Th1 and Th17 infiltration in the CNS of EAE. Furthermore, 4-EG suppressed Th1 and Th17 differentiation in the periphery of EAE and in vitro Th1 and Th17 cultures. Finally, we found 4-EG induced HO-1 expression in the CNS of EAE in vivo as well as in MG, BV2 cells, and macrophages in vitro.

(Continued on next page)

\footnotetext{
* Correspondence: jimyen@iu.edu

'Department of Microbiology and Immunology, Indiana University School of Medicine, 2101 E. Coliseum Boulevard, Fort Wayne, IN 46805, USA

Full list of author information is available at the end of the article
}

(c) The Author(s). 2021 Open Access This article is licensed under a Creative Commons Attribution 4.0 International License, which permits use, sharing, adaptation, distribution and reproduction in any medium or format, as long as you give appropriate credit to the original author(s) and the source, provide a link to the Creative Commons licence, and indicate if changes were made. The images or other third party material in this article are included in the article's Creative Commons licence, unless indicated otherwise in a credit line to the material. If material is not included in the article's Creative Commons licence and your intended use is not permitted by statutory regulation or exceeds the permitted use, you will need to obtain permission directly from the copyright holder. To view a copy of this licence, visit http://creativecommons.org/licenses/by/4.0/ The Creative Commons Public Domain Dedication waiver (http://creativecommons.org/publicdomain/zero/1.0/) applies to the data made available in this article, unless otherwise stated in a credit line to the data. 
(Continued from previous page)

Conclusions: Our work demonstrates that 4-EG confers protection against autoimmune disease EAE through modulating neuroinflammation and inhibiting Th1 and Th17 differentiation, suggesting 4-EG, a natural compound, could be potentially developed as a therapeutic agent for the treatment of MS/EAE.

Keywords: MS/EAE, 4-EG, Microglia, Th1/Th17, Neuroinflammation, Blood-brain barrier

\section{Introduction}

Multiple sclerosis (MS) is a progressive autoimmune disease characterized by the accumulation of pathogenic inflammatory immune cells in the central nervous system (CNS) that subsequently causes focal inflammation, demyelination, axonal injury, and neuronal damage $[1,2]$. Experimental autoimmune encephalomyelitis (EAE) is a well-established murine model mimicking the key features of MS, making it a useful tool for MS research and drug discovery [1]. T cells specific for CNS antigens are reported to play a major role in the disease development of both MS and EAE [1,2]. During the disease progression, autoreactive $\mathrm{T}$ cells augment $\mathrm{CNS}$ inflammation by secreting a variety of pro-inflammatory cytokines, including IFN $\gamma$, IL-17, and GM-CSF $[3,4]$. In addition, the CNS-resident microglia (MG) have been shown to promote differentiation and reactivation of pathogenic $\mathrm{T}$ cells [5].

The dietary consumption of foods rich in phenols has been attributed to numerous health benefits, including lowering rates of chronic diseases, such as Alzheimer's disease, Parkinson's disease, diabetes, cardiovascular disease, and inflammation [6, 7]. One such molecule, 4ethylguaiacol (4-ethyl-2-methoxyphenol, hereinafter referred to as 4-EG), is a phenolic compound with the molecular formula $\mathrm{C}_{9} \mathrm{H}_{12} \mathrm{O}_{2}$ and belongs to the class of organic compounds known as methoxyphenols $[8,9]$. 4EG and other methoxyphenols have been detected in wine and beer produced by the spoilage yeast Brettanomyces [10]. In addition, 4-EG can be detected in several different foods, such as green, orange, and yellow bell peppers; corn; sesame seeds; and coffee [9]. There has been growing evidence showing that phenolic compounds exert anti-inflammatory effects through inhibiting the production of TNF $\alpha$, IL-6, IL-1 $\beta$, and cyclooxygenase- $2[8,11]$. The anti-inflammatory effects of 4-EG were shown to be mediated through the inhibition of $\mathrm{NFK}_{\mathrm{K}} \mathrm{B}$ and inflammasome activation that led to the suppression of inflammatory cytokines in THP-1 human monocytic cells [8]. Furthermore, 4-EG was shown to induce nuclear factor erythroid 2related factor 2 (Nrf2) signaling in LPS-treated THP-1 cells, and silencing Nrf2 significantly promoted NF- $\mathrm{KB}$ expression in the nucleus of LPS-stimulated THP-1 cells [8], suggesting that 4-EG-induced antiinflammatory effects may be mediated through the induction of the Nrf2/heme oxygenase-1 (HO-1) pathway.

The induction of transcription factor Nrf2 is an antioxidant defense mechanism elicited to counteract oxidative stress in cells [12]. In addition, the induction of Nrf2 has been shown to provide potent antiinflammatory effects [13-16]. The activity of Nrf2 is regulated via interaction with its repressor, Keap1. Under the basal conditions, Keap1 binds Nrf2, giving rise to a Keap1-associated ubiquitin ligase complex that results in ubiquitination and subsequent Nrf2 degradation. In response to oxidative stress, Nrf2 escapes Keap1-mediated repression and is translocated into the nucleus. In the nucleus, Nrf2 binds to the antioxidant response element, inducing the transcription of phase II detoxication enzymes, including $\mathrm{NAD}(\mathrm{P}) \mathrm{H}$ quinone dehydrogenase 1 (NQO1), glutamate-cysteine ligase catalytic subunit (GCLC), and the anti-inflammatory enzyme HO-1 [17, 18].

Currently, whether 4-EG exerts anti-inflammatory effects on modulating the CNS immune responses remains unknown. Thus, in this study, we explored the therapeutic effect of 4-EG on the CNS autoimmune disease, MS, using the animal model of EAE, and investigated the cellular and molecular mechanisms underlying the protective effects of 4-EG in EAE. Our results showed that 4-EG not only ameliorated the disease severity in C57BL/6 chronic EAE but also mitigated disease progression in SJL/J relapsing-remitting EAE. Further investigations revealed that 4-EG suppressed MG activation, inhibited Th1 and Th17 infiltration, and mitigated blood-brain barrier (BBB) disruption in the CNS of EAE. In addition, 4-EG suppressed Th1 and Th17 differentiation in the periphery of EAE. Finally, we identified that 4-EG promoted $\mathrm{HO}-1$ expression in the CNS of EAE, and 4-EG-mediated HO-1 upregulation was further confirmed in primary MG, BV2 cells, and primary macrophages. Our findings provide the first evidence that 4EG could be developed as a therapeutic agent for the treatment of MS/EAE.

\section{Material and methods \\ Animals}

Female C57BL/6 and SJL/J mice were purchased from the Jackson Laboratory (Bar Harbor, ME). Mice were housed and bred in the animal facility with controlled 
temperature, humidity, and a 12-h light/dark alternate cycle. All animal studies performed in this study were approved by the Purdue University Animal Care and Use Committee (PACUC) and conducted in strict compliance with the National Institutes of Health Guidelines for the Care and Use of Laboratory Animals.

\section{EAE induction}

Female C57BL/6 and SJL/J mice (7-9 weeks) were immunized with $\mathrm{MOG}_{35-55}$ and $\mathrm{PLP}_{139-151}$, respectively, to induce EAE as previously described [15]. Briefly, for the chronic EAE model, C57BL/6 mice were subcutaneously immunized with MOG $_{35-55}(200 \mu \mathrm{g}$ per mouse) emulsified with complete Freund's adjuvant (CFA) (MilliporeSigma, St. Louis, MO, USA) containing Mycobacterium tuberculosis H37 RA (BD, Sparks, MD, USA) with the final concentration of $2 \mathrm{mg} / \mathrm{ml}$ on day 0 . For the relapsing-remitting EAE model, SJL/J mice were subcutaneously immunized with PLP $_{139-151}(100 \mu \mathrm{g}$ per mouse) emulsified with CFA containing Mycobacterium tuberculosis H37 RA with the final concentration of 2 $\mathrm{mg} / \mathrm{ml}$ on day 0 . Immunized C57BL/6 and SJL/J mice were then i.p. administered with $200 \mathrm{ng}$ pertussis toxin (List Biological Labs, Campbell, CA, USA) on day 0 and day 2. For the treatment, 4-EG (MilliporeSigma) dissolved in phosphate-buffered saline (PBS) was i.p administrated to C57BL/6 EAE mice daily starting from day 3 post-immunization till day 30 post-immunization or to SJL/J EAE mice daily starting from the first remission phase (disease score $\leq 1.5$ ) for 20 days. The vehicle was administered with an equal volume of PBS. EAE mice were monitored daily to assess disease scores. The disease scores were determined based on the following criteria: 0 , no clinical signs; 1 , limp tail or hind limb weakness; 2, limp tail and hind limb weakness; 3 , partial hind limb paralysis; 4, complete hind limb paralysis; and 5, moribund state. EAE incidence, mortality, onset of disease, maximum score, and cumulative score (sum of disease scores) were also assessed. The investigators evaluating EAE disease scores were blinded to the EAE groups. A summarized table that describes the tissue distribution for different experiments is included in Table S1.

\section{CNS mononuclear cell isolation}

C57BL/6 EAE mice were anesthetized and perfused with ice-cold PBS. The brains and spinal cords harvested from vehicle- and 4-EG-treated EAE mice were excised and homogenized with $1 \times$ HBSS buffer containing collagenase. Dissociated cells were then filtered through 70$\mu \mathrm{m}$ nylon meshes and pelleted by centrifugation. After resuspension, cells were subjected to 30/70 Percoll density gradient, and the mononuclear cells were harvested from the interface between 30 and 70\% Percoll (GE,
Pittsburgh, PA, USA). After extensive washing with PBS, cells were collected and subjected to flow cytometry analysis (BD FACSVerse).

\section{In vitro Th1 and Th17 differentiation}

Splenocytes $\left(3 \times 10^{6}\right.$ cells/well $)$ harvested from the spleen of C57BL/6 mice were stimulated with pre-coated anti-mouse CD3 antibody (3 $\mu \mathrm{g} / \mathrm{ml}$, clone: $145-2 \mathrm{C} 11$, BioLegend, San Diego, CA) and soluble anti-mouse CD28 antibody ( $2 \mu \mathrm{g} / \mathrm{ml}$, clone: 37.51 , BioLegend) in the presence of IL-12 (10 ng/ml, BioLegend) for Th1 differentiation or IL-6 (20 ng/ml, BioLegend), TGF $\beta$ (10 ng/ $\mathrm{ml}$, BioLegend), and anti-mouse IFN $\gamma$ antibody $(5 \mu \mathrm{g} / \mathrm{ml}$, clone: R4-6A2, BioLegend) for Th17 differentiation. T cells were treated with vehicle or 4-EG $200 \mu \mathrm{M}$ during Th1 and Th17 differentiation. Forty-eight and 72 hours later, cells were then collected and subjected to flow cytometry analysis for intracellular cytokine expression.

\section{Flow cytometry analysis for intracellular cytokine and surface marker expression}

For intracellular cytokine analysis, mononuclear cells isolated from the brain and spinal cord of C57BL/6 EAE mice, splenocytes harvested from C57BL/6 EAE mice, and naive splenocytes differentiated into Th1 and Th17 cells in vitro were stimulated with phorbol myristate acetate $(50 \mathrm{ng} / \mathrm{ml}$, MilliporeSigma) and ionomycin (750 $\mathrm{ng} / \mathrm{ml}$, MilliporeSigma) in the presence of Brefeldin A solution $(1 \mu \mathrm{l} / \mathrm{ml}$, BioLegend). After 5 hours of incubation, cells were then harvested and stained with APCconjugated anti-mouse CD4 (Clone: RM4-5, BioLegend) in the presence of 7-aminoactinomycin D (7-AAD) (BioLegend). Following wash, cells were fixed and then permeabilized followed by intracellular staining with $\mathrm{PE} /$ Cy7-conjugated anti-mouse IFNY (clone: XMG1.2, BioLegend) and PE-conjugated anti-mouse GM-CSF (Clone: MP1-22E9, BioLegend). In addition, cells were stained with Alexa Fluor 488-conjugated anti-mouse CD4 (clone: RM4-5, BioLegend) in the presence of 7-AAD followed by intracellular staining with APC-conjugated anti-mouse IL-17 (clone: TC11-18H10.1, BioLegend). The intracellular expression of IFN $\gamma$, IL-17, and GMCSF in $\mathrm{CD}^{+}$cells was then determined by flow cytometry analysis, and the flow gating strategies are shown in Fig. S1. For MG surface marker analysis, mononuclear cells isolated from the brain and spinal cord of C57BL/6 EAE mice were stained with APC-conjugated antimouse CD11b (clone: M1/70, BioLegend), Alexa Fluor 488-conjugated anti-mouse CD45 (clone: 30-F11, BioLegend), PE/Cy7-conjugated anti-mouse CD80 (clone: 1610A1, BioLegend), and PE-conjugated anti-mouse CD86 (clone: GL-1, BioLegend). CD80 and CD86 expression on $\mathrm{CD} 45^{\text {int }} \mathrm{CD} 11 \mathrm{~b}^{+}$MG were then determined by flow cytometry analysis. 
Histopathology and immunohistochemistry (IHC) staining The L4-L6 segments of the spinal cords harvested from C57BL/6 EAE mice were fixed with $4 \%$ paraformaldehyde (MilliporeSigma). For histopathology staining, paraffin-embedded spinal cord sections (8- $\mu$ m-thick) were subjected to hematoxylin and eosin (H\&E) staining, and $H \& E$ images were captured with a fluorescence microscope ( $\times 10$ and $\times 20$, BX53, Olympus). The areas of cell infiltration were determined based on the observation of stained cells near the edge of the spinal cords, and the total areas of cell infiltration were then quantified by ImageJ. For IHC staining, the fixed L4-L6 segments were subjected to sucrose dehydration and then embedded in OCT followed by cryosections. The sections were blocked with $5 \%$ goat serum and then stained with anti-MMP9 antibodies (1:100, Cat\# 10375-2-AP, Proteintech) at $4{ }^{\circ} \mathrm{C}$ overnight. After rinsing with PBS, the sections were stained with secondary antibodies (Alexa Fluor 594 goat anti-rabbit secondary antibody, 1: 1000, Invitrogen, Waltham, MA, USA) at room temperature for $2 \mathrm{~h}$. After wash, the sections were further stained with Alexa Fluor 488 anti-Iba1 antibodies (1:100, Abcam, EPR16588, Cambridge, UK) at room temperature for $2 \mathrm{~h}$ followed by coverslipping with ProLong Gold antifade mountant containing DAPI (Invitrogen). Immunofluorescence images of spinal cord tissues were captured with a fluorescence microscope $(\times 20$, BX53, Olympus). The slides stained with only secondary antibodies were served as negative controls. $\mathrm{Iba}^{+}$cells were determined based on the cells with morphology of large cell body and short dendrites, indicating stages 3 to 5 of MG activation [19]. To determine MMP9 fluorescence intensity, negative controls were used to set up the color threshold of MMP9 fluorescence signals, and the mean of MMP9 fluorescence signals (fluorescence intensity) detected on the slides of spinal cord samples prepared from vehicle- and 4-EG-treated EAE mice was calculated by ImageJ.

\section{Evans blue BBB permeability assay}

The BBB permeability was determined based on the leakage of Evans blue as previously described [15]. C57BL/6 EAE mice were i.v. administered with $4 \mathrm{ml} / \mathrm{kg}$ $2 \%(\mathrm{w} / \mathrm{v})$ Evans blue dye dissolved with saline into the lateral tail vein. Two hours after injection, mice were anesthetized and perfused with PBS. The brain and spinal cord were harvested and subjected to imaging to evaluate Evans blue leakage. The tissues were then weighted and homogenized in 50\% trichloroacetic acid (TCA) solution. After overnight incubation at $4{ }^{\circ} \mathrm{C}$, the samples were then centrifuged, and the supernatants were extracted and diluted with $95 \%$ ethanol in the ratio of 1:3. The amount of Evans blue in the brain and spinal cord tissues was then measured with excitation at 540/
$25 \mathrm{~nm}$ and emission at $640 / 40 \mathrm{~nm}$ by the Synergy ${ }^{\mathrm{TM}} \mathrm{HT}$ microplate reader (BioTek, Winooski, VT, USA).

\section{Western blot analysis}

Spinal cord and brain tissues harvested from C57BL/6 EAE mice were lysed in radioimmunoprecipitation assay (RIPA) buffer containing $50 \mathrm{mM}$ Tris- $\mathrm{HCl}$ (pH8.0), $150 \mathrm{mM} \mathrm{NaCl}, 1 \% \mathrm{NP}-40,0.5 \%$ sodium deoxycholate, $1 \mathrm{mM}$ PMSF, and $1 \times$ protease inhibitor cocktail with $0.3 \%$ SDS. Following tissue homogenization, the concentrations of tissue proteins were measured by using the Pierce $^{\mathrm{Tu}}$ BCA Protein Assay Kit (Thermo Fisher Scientific). The lysate samples were then subjected to electrophoresis and transferred onto the polyvinylidene difluoride membranes (MilliporeSigma). The membranes were then incubated with primary antibodies of MMP9 (1:1000, clone: L51/82, BioLegend), MMP3 (1:1000, clone: M4405F10, BioLegend), Nrf2 (1:100, Cat\# 16396-I-AP, Proteintech), HO-1 (1:2000, Cat\# 10701-I-AP, Proteintech), or $\beta$-actin (BD Biosciences) overnight followed by incubation with horseradish peroxidase (HRP)-conjugated secondary antibodies (BD Biosciences) for 1 hour. Immunoreactivities were then visualized by Immobilon $^{\text {Tw }}$ Western Chemiluminescent HRP Substrate (MilliporeSigma). The intensity of designated protein bands was densitometrically quantified and then normalized with $\beta$-actin by using the Image ProPlus 4.5 (Media Cybernetics, Rockville, MD, USA).

\section{Cell culture}

Primary MG were generated from P1-P2 neonatal mice as previously described [20]. Briefly, cerebral cortical cells were harvested from P1-P2 neonatal mice and then plated in $75-\mathrm{cm}^{2}$ culture flasks in a complete medium (DMEM/F12 supplemented with 10\% FBS). At day 4 and 8 after plating, the medium was removed and replenished with a complete medium containing $10 \mathrm{ng} / \mathrm{ml}$ GM-CSF. The flasks were then shaken at $37{ }^{\circ} \mathrm{C}$ for 30 minutes at day 12, and MG were harvested from supernatants for experiments. The mouse microglial cell line BV2 cells were grown in $25-\mathrm{cm}^{2}$ flasks. After cells were grown to confluence, cells were trypsinized and seeded on tissue culture plates followed by indicated stimulations. Primary macrophages were generated from bone marrow cells as previously described [21]. Briefly, bone marrow cells were cultured with a complete RPMI 1640 medium containing $10 \mathrm{ng} / \mathrm{ml} \mathrm{M-CSF}$. Cells were replenished with a fresh medium containing $10 \mathrm{ng} / \mathrm{ml} \mathrm{M-CSF}$ at day 3 and collected at day 7 for experiments.

\section{Quantitative PCR}

The expression of Ho-1, NQO1, and Gclc was detected by SYBR green-based quantitative PCR (Q- 
PCR). The primers used were as follows: Ho-1, sense 5'-GCTGGTGATGGCTTCCTTGT-3' and antisense 5'-ACTGGGTTCTGCTTGTTGCG-3'; Nqo1, sense 5'-GGCCCATTCAGAGAAGACAT-3' and antisense 5'-TTCGAGTACCTCCCATCCTC-3'; Gclc, sense 5'CCTACGGAGGAA CGATGTCT-3' and antisense 5' GGAATGAAGTGATGGTGCAG-3'; and $\beta$-actin, sense $5{ }^{\prime}$-TCCACCACCACAGCTGAGAGG-3' and antisense $\quad 5^{\prime}$-CAGCTTCTCTTTGATGTCACGC-3'. Q-PCR was performed using the Applied Biosystems StepOnePlus ${ }^{\text {TM }}$ Real-Time PCR System. The levels of gene expression were determined by the cycle threshold $(\mathrm{Ct})$ values followed by quantification using standard curves. The results were then normalized to $\beta$ actin from the same samples to obtain relative changes of gene expression.

\section{Statistical analysis}

All results were presented as mean \pm SEM. For samples that passed the Shapiro-Wilk normality test, comparisons between two groups were performed by unpaired $t$ test, whereas comparisons among multiple groups were performed by one-way ANOVA followed by Tukey post hoc test. Two-way ANOVA test was used for statistical analysis of EAE clinical scores. For samples that did not pass the normality test, comparisons between two groups were performed by Mann-Whitney $U$ test. Statistical analysis was performed by using the GraphPad Prism 8 software, and statistical significance was determined as $p$ values $\leq 0.05$

\section{Results}

4-EG ameliorates disease severity in chronic EAE and alleviates disease progression in relapsing-remitting $E A E$ To explore whether 4-EG offers protection against EAE, we evaluated the effects of 4-EG on the amelioration of disease severity in $\mathrm{C} 57 \mathrm{BL} / 6$ chronic EAE models. $\mathrm{MOG}_{35-55}$-immunized C57BL/6 mice were i.p. administered with vehicle or different doses of 4-EG (50, 100, and $200 \mathrm{mg} / \mathrm{kg}$ ) daily starting from day 3 postimmunization, and the clinical scores of vehicle- and 4EG-treated EAE mice were monitored for 30 days. We observed 4-EG $50 \mathrm{mg} / \mathrm{kg}$ offered little protection in
(A)

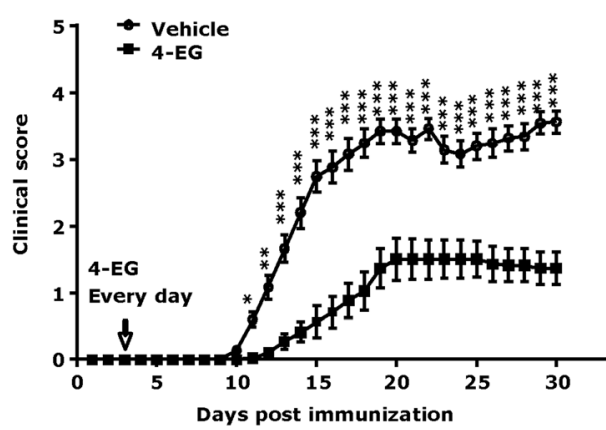

(B)

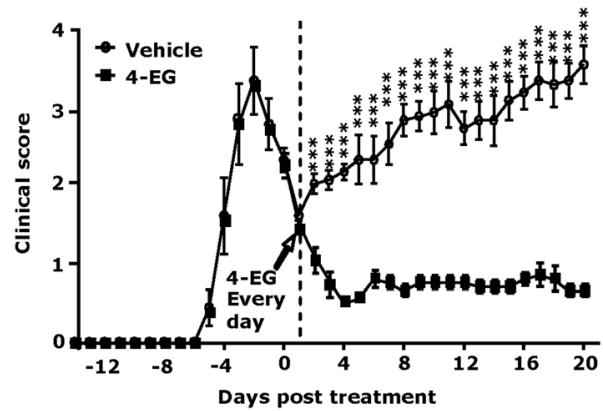

\begin{tabular}{|c|c|c|}
\hline & Vehicle & $\begin{array}{c}4-\mathrm{EG} \\
(100 \mathrm{mg} / \mathrm{kg})\end{array}$ \\
\hline Incidence & $20 / 20$ & $20 / 20$ \\
\hline Mortality & $0 / 20$ & $0 / 20$ \\
\hline $\begin{array}{c}\text { Onset of } \\
\text { disease }\end{array}$ & $10.3 \pm 0.5$ & $11.8 \pm 1.0$ \\
\hline $\begin{array}{c}\text { Maximum } \\
\text { score }\end{array}$ & $4.0 \pm 0.4$ & $2.1 \pm 2.0 * *$ \\
\hline $\begin{array}{c}\text { Cumulative } \\
\text { score }\end{array}$ & $62.2 \pm 0.1$ & $23.5 \pm 0.6 * * *$ \\
\hline
\end{tabular}

\begin{tabular}{|c|c|c|}
\hline & Vehicle & $\begin{array}{c}4-\mathrm{EG} \\
(100 \mathrm{mg} / \mathrm{kg})\end{array}$ \\
\hline Incidence & $10 / 10$ & $10 / 10$ \\
\hline Mortality & $0 / 10$ & $0 / 10$ \\
\hline $\begin{array}{c}\text { Onset of } \\
\text { disease }\end{array}$ & $10.4 \pm 2.1$ & $11.1 \pm 1.3$ \\
\hline $\begin{array}{c}\text { Maximum } \\
\text { score post } \\
\text { treatment }\end{array}$ & $4.0 \pm 0$ & $1.3 \pm 0.4 * * *$ \\
\hline $\begin{array}{c}\text { Cumulative } \\
\text { score post } \\
\text { treatment }\end{array}$ & $69.8 \pm 0.5$ & $15.5 \pm 0.2 * * *$ \\
\hline
\end{tabular}

Fig. 1 4-EG ameliorates disease severity in chronic EAE and alleviates disease progression in relapsing-remitting EAE. a C57BL/6 mice were immunized with $\mathrm{MOG}_{35-55}$ and then i.p. injected with vehicle or 4-EG $100 \mathrm{mg} / \mathrm{kg}$ ( $n=20 / \mathrm{group}$ ) daily starting from day 3 post-immunization. The clinical score of EAE animals was followed for 30 days. b SJL/J mice were immunized with PLP $139-151$ to induce EAE. Following the first remission and reaching disease score less than 1.5, SJL/J EAE mice were i.p. injected with vehicle or 4-EG $100 \mathrm{mg} / \mathrm{kg}$ ( $n=10 / \mathrm{group})$ daily. The clinical score of EAE mice was monitored for 20 days. Statistical significance of EAE clinical score was determined as ${ }^{*} p<0.05$, ${ }^{* *} p<0.01$, and ${ }^{* * *} p<0.001$ by twoway ANOVA test. EAE incidence, mortality, onset of disease, maximum score, and cumulative score of C57BL/6 and SJL/J EAE were also assessed. Statistical significance was determined as ${ }^{* *} p<0.01$ and ${ }^{* * *} p<0.001$ by Mann-Whitney $U$ test 


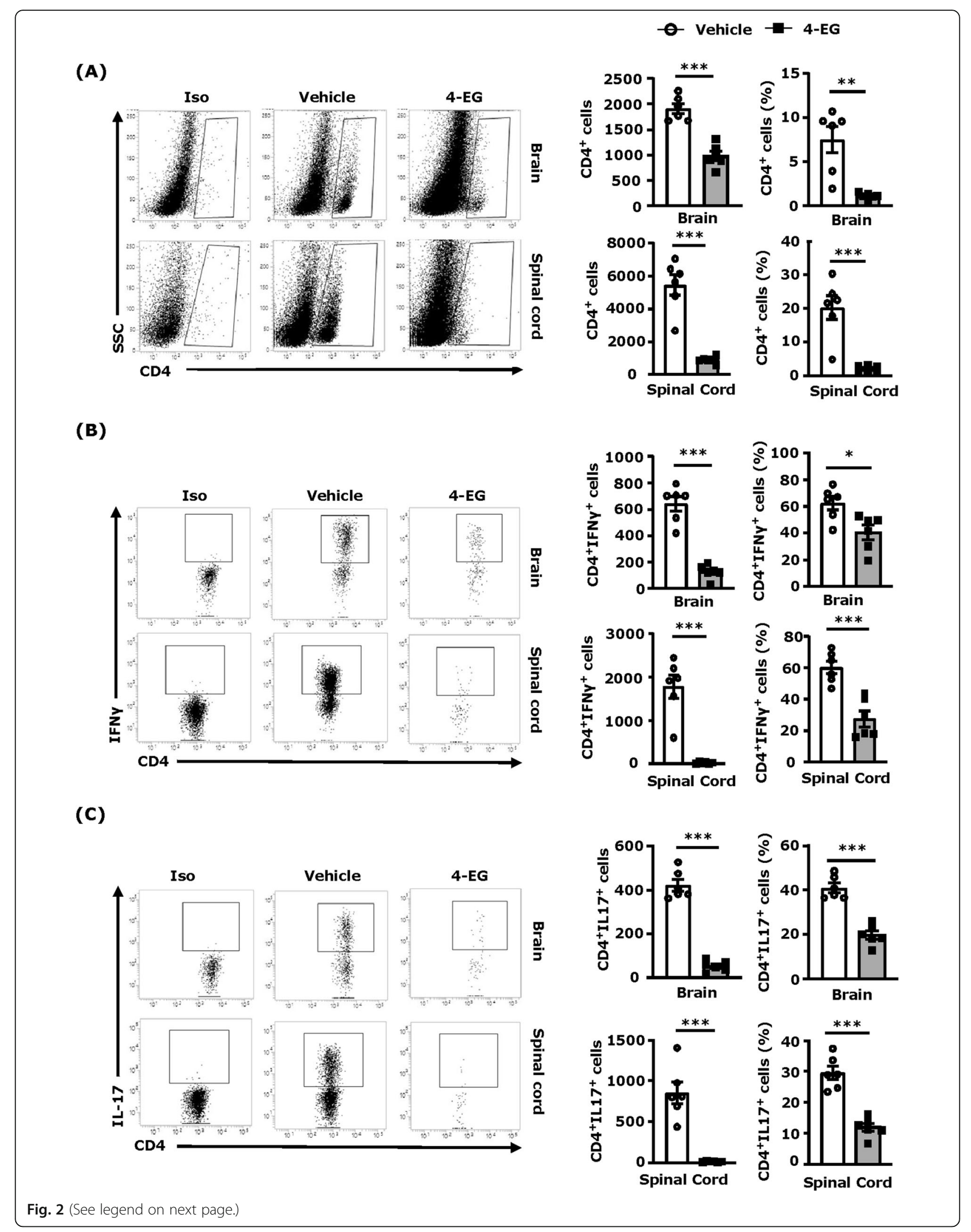




\section{(See figure on previous page.)}

Fig. 2 4-EG suppresses encephalitogenic Th1 and Th17 infiltration of the CNS in EAE. At day 11-13 post-immunization, mononuclear cells were isolated from the brain and spinal cord of vehicle- and 4-EG (100 mg/kg)-treated C57BL/6 EAE mice ( $n=6 /$ group), and the isolated mononuclear cells were then subjected to surface staining of CD4 followed by intracellular staining of IFNY and IL-17. $\mathbf{a}-\mathbf{c}$ The frequency determined by the percentages of $\mathrm{CD}^{+} \mathrm{T}$ cells in total acquired cells, and the percentages of IFNY- or IL-17-expressing $\mathrm{CD} 4^{+} \mathrm{T}$ cells in total $\mathrm{CD} 4^{+} \mathrm{T}$ cells were analyzed in the brain and spinal cord of vehicle- and 4-EG-treated EAE mice by flow cytometry analysis. a-c The number of CD4 ${ }^{+} \mathrm{T}$ cells, CD4 ${ }^{+}$ IFNY ${ }^{+} \mathrm{T}$ cells, and $\mathrm{CD} 4^{+} \mathrm{IL}-17^{+} \mathrm{T}$ cells in the brain and spinal cord of vehicle- and 4-EG-treated EAE mice was also determined. One representative flow result of each condition is shown. Isotype controls (Iso) were used as a negative control to determine cells positive for the surface expression of $\mathrm{CD} 4 \mathbf{a}$ or $\mathrm{CD}^{+}{ }^{+} \mathrm{T}$ cells positive for the intracellular expression of IFNy or IL-17 $\mathbf{b}, \mathbf{c}$. Data are representative of three independent experiments ( $n=4-6 /$ group per experiment). Statistical significance was determined as ${ }^{*} p<0.05,{ }^{* *} p<0.01$, and ${ }^{* * *} p<0.001$ by unpaired $t$ test

EAE. However, 4-EG $200 \mathrm{mg} / \mathrm{kg}$ exerted a toxic effect that resulted in $100 \%$ mortality in EAE mice. We found that 4-EG $100 \mathrm{mg} / \mathrm{kg}$ offered optimal protection in EAE and did not cause any toxicity in EAE mice (Fig. S2). Thus, the dose of $100 \mathrm{mg} / \mathrm{kg}$ 4-EG was selected and used throughout the studies. Using the dose of $100 \mathrm{mg} /$ $\mathrm{kg}$ 4-EG for the treatment of EAE, we found that although vehicle- and 4-EG-treated EAE mice had a comparable outcome with regard to the onset of disease, 4EG treatment ameliorated disease severity and significantly reduced both maximum and cumulative disease scores compared to vehicle treatment in EAE mice (maximum score, 4-EG $2.1 \pm 2.0$ vs. vehicle $4.0 \pm 0.4$; cumulative disease score, 4 -EG $23.5 \pm 0.6$ vs. vehicle $62.2 \pm$ 0.1) (Fig. 1a).

We then evaluated whether 4-EG exerted a therapeutic potential in the relapsing-remitting EAE model. SJL/J mice were immunized with $\mathrm{PLP}_{139-151}$ to induce relapsing-remitting EAE. After EAE mice entered the first remitting phase (disease score $\leq 1.5$ ), EAE mice were then administered with vehicle or 4-EG, and the disease scores of EAE mice were monitored for additional 20 days. Our results showed 4-EG treatment not only ameliorated disease severity but also prevented disease relapse in SJL/J EAE mice. In contrast, vehicle-treated SJL/ $J$ EAE mice further developed relapses accompanied with augmented disease scores. Our results showed that the maximum and cumulative scores post-treatment were $1.3 \pm 0.4$ and $15.5 \pm 0.2$ for 4-EG-treated EAE mice and $4.0 \pm 0$ and $69.8 \pm 0.5$ for vehicle-treated EAE controls, respectively (Fig. 1b). Collectively, our results demonstrate that 4-EG ameliorates disease severity in chronic EAE and attenuates disease progression in relapsing-remitting EAE, suggesting that 4-EG exerts protective and therapeutic effects in EAE.

\section{4-EG suppresses encephalitogenic Th1 and Th17 infiltration of the CNS in EAE}

Given that the CNS infiltration of encephalitogenic Th1 and Th17 exerts the main pathogenic effect on the induction of EAE, we evaluated whether 4-EG treatment modulated pathogenic $\mathrm{CD} 4^{+} \mathrm{T}$ cell infiltration of the CNS in C57BL/6 EAE mice. Mononuclear cells isolated from the brain and spinal cord of vehicle- and 4-EG- treated EAE mice were subjected to flow cytometry analysis to determine the number and frequency of the CNS infiltrating $\mathrm{CD}^{+}{ }^{+} \mathrm{T}$ cells as well as IFN $\gamma^{-}$and IL-17expressing $\mathrm{CD} 4^{+} \mathrm{T}$ cells in the brain and spinal cord of EAE. Our results showed that a large number of $\mathrm{CD} 4^{+} \mathrm{T}$ cells were observed in the brain and spinal cord of vehicle-treated EAE mice. In contrast, the number of $\mathrm{CD}_{4}^{+} \mathrm{T}$ cells was significantly reduced in the brain and spinal cord of 4-EG-treated EAE mice (Fig. 2a). Similarly, we observed that the frequency (\%) of $\mathrm{CD}^{+} \mathrm{T}$ cells in the brain and spinal cord was also significantly lower in 4-EG-treated EAE mice than vehicle-treated EAE controls (Fig. 2a). We further analyzed Th1 and Th17 cells in the CNS of EAE mice and found that the number and frequency of IFN $\gamma$ - and IL-17-expressing CD $4^{+} \mathrm{T}$ cells in the brain and spinal cord were significantly decreased in 4-EG-treated EAE mice compared to vehicle-treated EAE controls (Fig. 2b, c). Altogether, these results demonstrate that 4-EG suppresses Th1 and Th17 infiltration of the CNS that may contribute to its protective effects in EAE.

\section{4-EG inhibits Th1 and Th17 differentiation in vivo and in vitro}

To elucidate whether 4-EG modulates $\mathrm{CD} 4^{+} \mathrm{T}$ cell differentiation in the periphery that results in repressed Th1 and Th17 infiltration of the CNS in EAE, splenocytes were harvested from vehicle- and 4-EG-treated EAE mice at day 8 post-immunization followed by flow cytometry analysis to determine the level of IFN $\gamma$ - and IL-17-expressing $\mathrm{CD}^{+} \mathrm{T}$ cells. Our results showed that the frequency and number of IFN $\gamma$ - and IL17-expressing $\mathrm{CD}_{4}{ }^{+} \mathrm{T}$ cells were significantly lower in the spleen of 4EG-treated EAE mice compared to that of vehicletreated EAE controls (Fig. 3a), indicating 4-EG suppresses Th1 and Th17 differentiation in the periphery of EAE.

To further confirm the suppressive effect of 4-EG on Th1 and Th17 differentiation, splenocytes harvested from naive mice were differentiated into Th1 or Th17 cells in the presence or absence of $200 \mu \mathrm{M}$ 4-EG in vitro followed by flow cytometry analysis to determine the intracellular expression of IFNy and IL-17 in $\mathrm{CD}^{+} \mathrm{T}$ cells. Our results showed that 4-EG strongly inhibited 


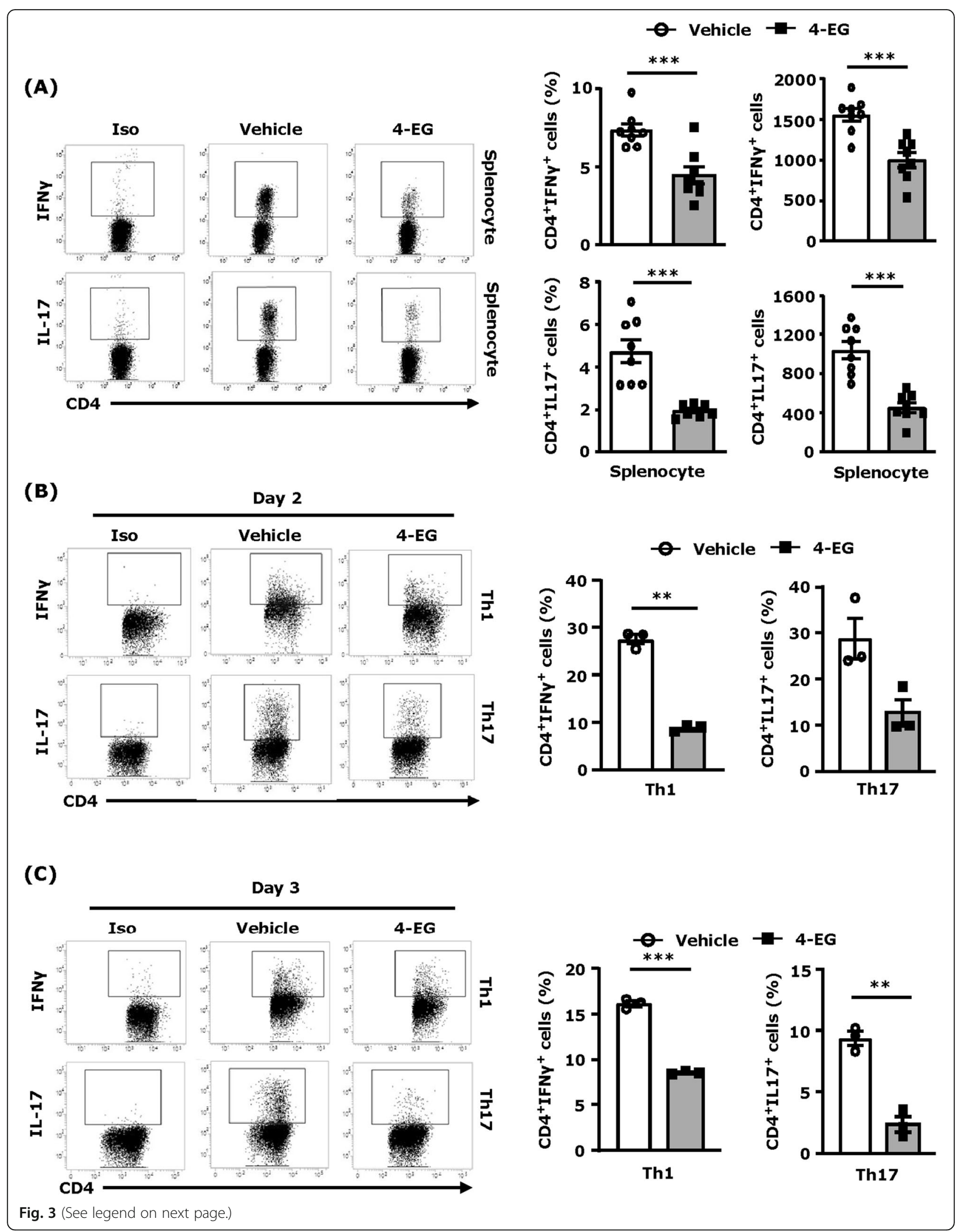


(See figure on previous page.)

Fig. 3 4-EG inhibits Th1 and Th17 differentiation in vivo and in vitro. a Splenocytes harvested from vehicle- and 4-EG (100 mg/kg)-treated C57BL/ $6 \mathrm{EAE}$ ( $n=8 /$ group) at day 8 post-immunization were subjected to flow cytometry analysis to determine the frequency and number of IFNY- and IL-17-expressing CD4 ${ }^{+} \mathrm{T}$ cells. b, c Naive splenocytes were polarized into Th1 and Th17 conditions in the presence or absence of 4-EG (200 $\mu \mathrm{M}$ ). Forty-eight and 72 hours after incubation, cells were collected and subjected to flow cytometry analysis to assess the frequency of intracellular expression of IFNy or IL-17 in CD4 ${ }^{+}$T cells. Data are representative of four independent experiments ( $n=2-3 /$ technique replicates per experiment). Isotype controls (Iso) were used as a negative control to determine CD4 ${ }^{+}$cells positive for intracellular expression of IFNy or IL-17. Statistical significance was determined as ${ }^{*} p<0.05,{ }^{* *} p<0.01$, and ${ }^{* *} p<0.001$ by unpaired $t$ test

Th1 and Th17 differentiation in vitro because the intracellular expression of IFNy and IL-17 in CD4 ${ }^{+} \mathrm{T}$ cells was suppressed at day 2 and day 3 post-treatment (Fig. $3 \mathrm{~b}, \mathrm{c})$. Although only live $\mathrm{CD} 4^{+} \mathrm{T}$ cells were gated to assess intracellular cytokine expression (Fig. S1C), we thought to evaluate whether 4-EG exerts toxicity in $\mathrm{T}$ cells. Our results showed that the cell viability of vehicleand $200 \mu \mathrm{M}$ 4-EG-treated Th1 and Th17 cells was comparable at day 2 post-treatment (Fig. S3). In addition, we observed vehicle- and $200 \mu \mathrm{M}$ 4-EG-treated Th1 cells displayed a similar viability at day 3 post-treatment (Fig. S3A). Although 4-EG decreased cell viability in Th17 cells about $25 \%$ at day 3 post-treatment (Fig. S3B), 4-EG exhibited a strong suppressive effect on Th17 differentiation that led to a more than 4-fold decrease in Th17 cells compared to vehicle (Fig. 3c). These results suggest that 4-EG-suppressed Th1 and Th17 differentiation is not due to its toxicity. Taken altogether, our results demonstrate that 4-EG suppresses pathogenic Th1 and Th17 differentiation in vitro and in vivo, and that may then result in decreased Th1 and Th17 infiltration in the brain and spinal cord of 4-EG-treated EAE mice.

\section{4-EG represses MG activation in EAE}

MG activation leads to increased production of proinflammatory cytokines and chemokines that induce neuroinflammation and promote the infiltration of inflammatory immune cells into the CNS of EAE [5]. We hypothesized that 4-EG might suppress MG activation to attenuate neuroinflammation and repress inflammatory immune cell infiltration of the CNS in EAE. To elucidate that, we isolated mononuclear cells from the brain and spinal cord of vehicle- and 4-EG-treated EAE mice and evaluated MG activation based on their expression of maturation markers, CD80 and CD86 [2224]. Although a similar level of $\mathrm{CD} 86^{+} \mathrm{MG}$ was observed in the CNS of vehicle- and 4-EG-treated EAE mice, our results showed that the number of $\mathrm{CD}^{+} 0^{+} \mathrm{MG}$ was profoundly reduced in the brain and spinal cord of 4-EGtreated EAE mice compared to those of vehicle-treated EAE controls (Fig. 4a). To further confirm our observation of 4-EG suppression of MG activation in EAE, we analyzed the level of $\mathrm{Iba}^{+}$cells in the spinal cord of vehicle- and 4-EG-treated EAE mice. Our results showed that there was a substantial reduction of $\mathrm{Iba}^{+}$cells in the spinal cord of 4-EG-treated EAE mice compared to that of vehicle-treated EAE controls (Fig. 4b). Altogether, these results illustrate that 4-EG suppresses MG activation to lessen neuroinflammation in EAE.

\section{4-EG mitigates BBB disruption, spinal cord pathology, and $M M P 3 / 9$ expression in EAE}

$\mathrm{BBB}$ disruption is considered to be the pathological hallmark of MS/EAE [25]. To explore the effects of 4-EG on $\mathrm{BBB}$ disruption in EAE, we examined the level of $\mathrm{BBB}$ leakage in vehicle- and 4-EG-treated EAE mice. At day 12-13 post-immunization, vehicle- and 4-EG-treated EAE mice were i.v. administered with Evans blue, and the level of Evans blue leakage in the brain and spinal cord tissues was then determined. Our results showed a clear image of Evans blue leakage in the brain and spinal cord of vehicle-treated EAE mice. In contrast, Evans blue leakage was not clearly observed in the CNS of 4EG-treated EAE mice (Fig. 5a, left). We then quantified the amount of Evans blue leakage in the CNS, and our results showed that the amount of Evans blue in the brain and spinal cord was significantly lower in 4-EGtreated EAE mice compared to vehicle-treated EAE controls (Fig. 5a, right). The histopathological features of the spinal cord in EAE were also assessed to determine whether increased BBB leakage positively correlates with elevated cell infiltrates in the CNS. We observed a large number of infiltrating immune cells in the spinal cord of vehicle-treated EAE mice. In contrast, only few infiltrating immune cells were observed in the spinal cord of 4EG-treated EAE mice (Fig. 5b).

Previous studies demonstrated that MMP3 and MMP9 contribute to the pathology of EAE/MS by aggravating $\mathrm{BBB}$ disruption [26, 27]. To elucidate whether the protective effect of 4-EG on maintaining $\mathrm{BBB}$ integrity in EAE was due to modulation of MMP3 and MMP9 expression, the brain and spinal cord tissues harvested from vehicle- and 4-EG-treated EAE mice were subjected to western blot analysis to determine MMP3 and MMP9 expression. Our results showed that both MMP3 and MMP9 were highly upregulated in the brain and spinal cord of vehicle-treated EAE mice (Fig. 5c). In contrast, the expression of MMP3 and MMP9 was largely suppressed in the brain and spinal cord of 4-EG-treated EAE mice (Fig. 5c). Furthermore, immunofluorescence 
(A)
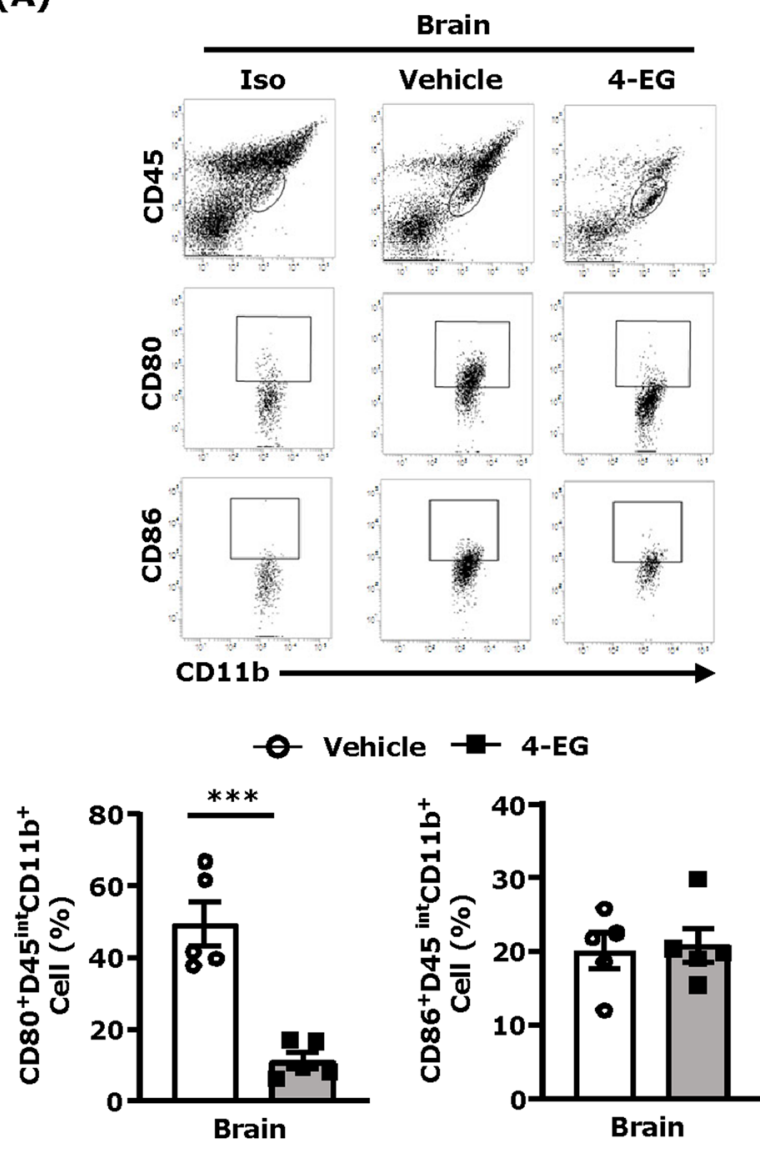

(B)

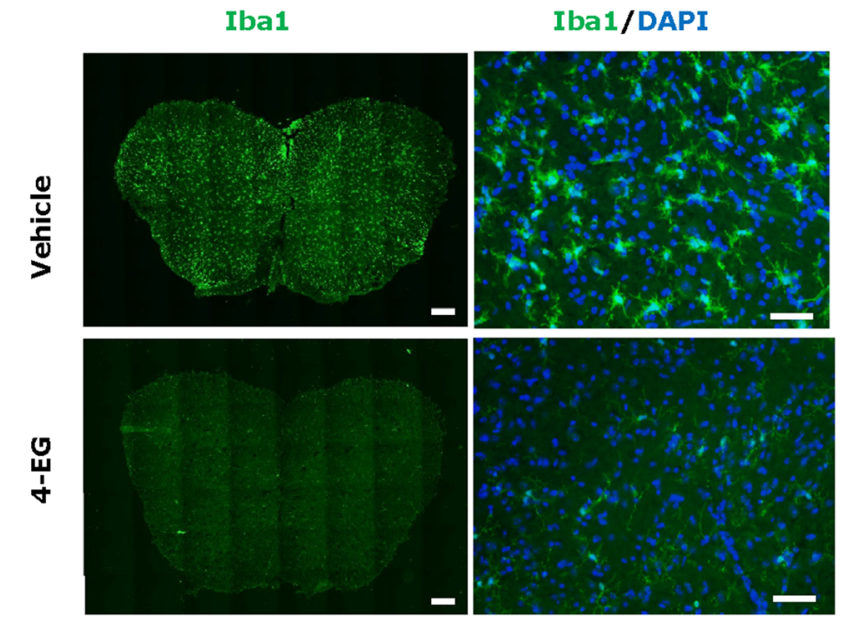

Spinal Cord
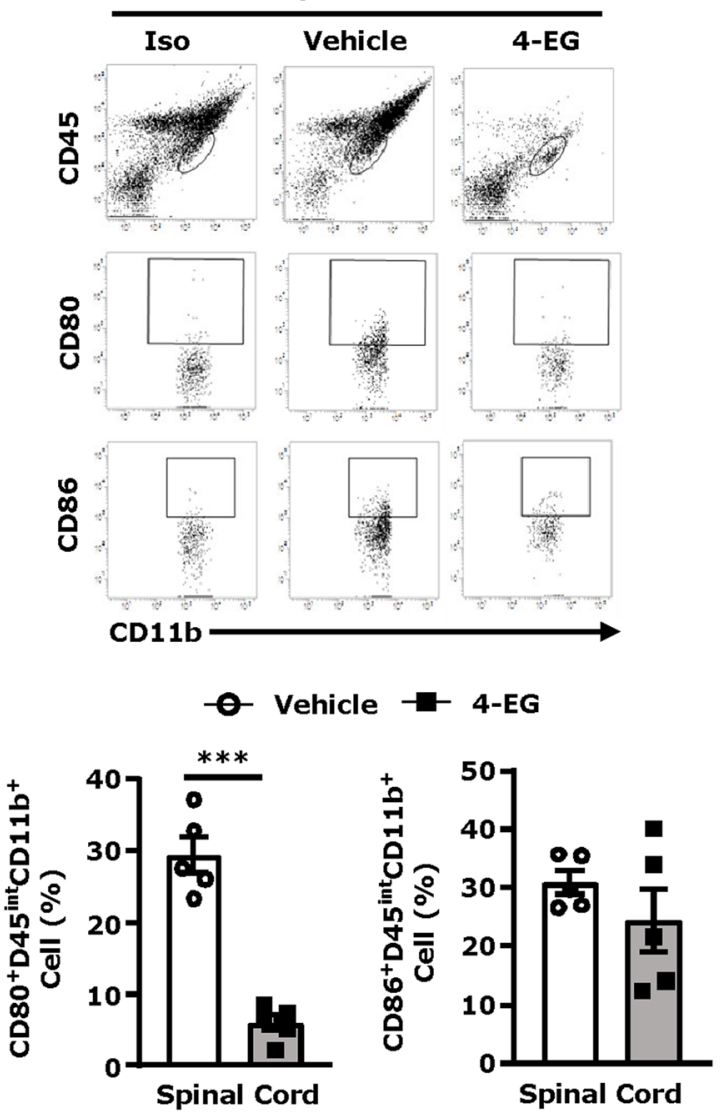

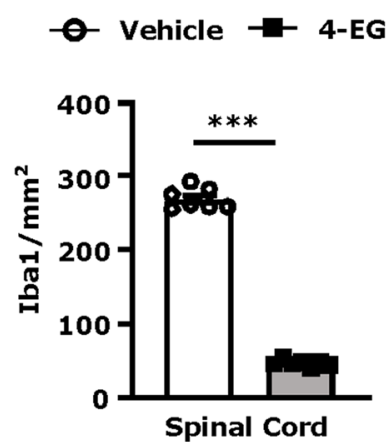

Fig. 4 4-EG represses MG activation in EAE. a At day 12-13 post-immunization, mononuclear cells were isolated from the brain and spinal cord of vehicle- and 4-EG (100 mg/kg)-treated C57BL/6 EAE mice followed by flow cytometry analysis to determine CD80 and CD86 expression on CD45 $5^{\text {int }} \mathrm{CD} 11 \mathrm{~b}^{+} \mathrm{MG}$ ( $n=5$ /group). Isotype controls (Iso) were used as a negative control to determine MG positive for CD80 or CD86 expression. Data are representative of two independent experiments ( $n=5 /$ group per experiment). $\mathbf{b}$ The lumbar regions of spinal cord tissues were collected from vehicle- and 4-EG-treated C57BL/6 EAE mice ( $n=7 /$ group) followed by immunofluorescence analysis to determine cells positive for Iba1 expression. The number of $\mathrm{Iba}^{+}$cells was calculated and quantified under $\times 20$ magnification. Scale bars, $200 \mu \mathrm{m}(\times 10$, left image), $50 \mu \mathrm{m}(\times 20$, right image). Statistical significance was determined as ${ }^{* * *} p<0.001$ by unpaired $t$ test 
analysis showed that MMP9 was highly expressed in the lumbar region of the spinal cord of vehicle-treated EAE mice and displayed as a secreted form as well as an intracellular form that was co-localized with $\mathrm{Iba}^{+}$cells. On the contrary, MMP9 expression was strongly suppressed in the spinal cord of 4-EG-treated EAE mice (Fig. 5d). Taken altogether, our results demonstrate that 4-EG mitigates EAE-induced BBB disruption that may be mediated through the anti-inflammatory effect of 4EG on the suppression of MMP3 and MMP9 production.

\section{4-EG suppresses GM-CSF expression in vivo and in vitro}

GM-CSF has been reported to play an essential role in the development and progression of EAE [3]. Although various cell types produce GM-CSF that include T cells, monocytes/macrophages, and endothelial cells [28], GM-CSF-producing $\mathrm{CD}^{+}{ }^{+} \mathrm{T}$ cells have been shown to be pivotal for EAE development [3]. To explore whether 4-EG affects GM-CSF production in EAE, splenocytes and mononuclear cells isolated from the brain and spinal cord of vehicle- and 4-EG-treated EAE mice were subjected to flow cytometry analysis to determine the frequency and number of GM-CSF-expressingproducing $\mathrm{CD}^{+}{ }^{+} \mathrm{T}$ cells. Our results showed that 4-EG treatment decreased the frequency and number of GM-CSFexpressing $\mathrm{CD}_{4}^{+} \mathrm{T}$ cells in the spleen of EAE mice, demonstrating that 4-EG inhibits the differentiation of GM-CSF-expressing $\mathrm{CD} 4^{+} \mathrm{T}$ cells in the periphery of EAE (Fig. 6a, top). Consequently, we observed a significant reduction of $\mathrm{GM}_{-} \mathrm{CSF}^{+} \mathrm{CD} 4^{+} \mathrm{T}$ cells in the brain and spinal cord of 4-EG-treated EAE mice compared to those of vehicle-treated EAE controls (Fig. 6a, middle and bottom).

To investigate whether 4-EG exerts a direct effect on the suppression of GM-CSF production in $\mathrm{CD}^{+} \mathrm{T}$ cells, splenocytes were harvested and differentiated into Th1 cells in the presence or absence of 4-EG, and the intracellular expression of GM-CSF in Th1 cells was then analyzed. Our results showed that the frequency of GMCSF-expressing $\mathrm{CD} 4^{+} \mathrm{T}$ cells was significantly decreased in 4-EG-treated Th1 cells compared to vehicle-treated Th1 controls (Fig. 6b). Collectively, these results demonstrate that 4-EG suppresses GM-CSF production in $\mathrm{CD} 4^{+} \mathrm{T}$ cells in vitro and in vivo.

\section{4-EG induces HO-1 expression in vivo and in vitro}

Induction of $\mathrm{Nrf} 2 / \mathrm{HO}-1$ pathway in $\mathrm{EAE}$ has been shown to offer protection against EAE [29-31]. Previously, studies showed that 4-EG induced HO-1 expression in THP-1 cells [8]. To elucidate whether 4-EG induces $\mathrm{Nrf} 2 / \mathrm{HO}-1$ pathway to offer protection against EAE, the level of Nrf2 and HO-1 expression was measured in the spinal cord of vehicle- and 4-EG treated-
EAE mice. We observed increased expression of Nrf2 and HO-1 in the spinal cord of 4-EG-treated EAE mice compared to that of vehicle-treated EAE controls (Fig. 7a).

Nrf2 activation contributes to the induction of phase II detoxification and anti-oxidant enzymes, including HO-1, Gclc, and NQO1 [32]. To confirm the effect of 4EG on the induction of the $\mathrm{Nrf} 2 / \mathrm{HO}-1$ pathway, primary MG, BV2 cells, and primary macrophages were activated with LPS in the presence or absence of 4-EG in a timedependent manner, and the expression of HO-1, Gclc, and NQO1 was then measured. Our results showed that 4-EG induced the expression of all three enzymes in MG, BV2 cells, and macrophages (Fig. 7b). Altogether, these results demonstrate that 4-EG induces HO-1 expression in vitro and in vivo, and 4-EG-induced HO-1 expression in the CNS of EAE may contribute to its protective effect on the amelioration of EAE.

\section{Discussion}

4-EG, a phenolic compound, has been reported to be a potential anti-inflammatory modulator through repressing the activation of $\mathrm{NFKB}$ and inflammasome, and inhibiting the production of inflammatory cytokines [8]. However, it remains unknown whether 4EG exerts anti-inflammatory effects on the modulation of CNS diseases. In this study, we evaluated the therapeutic effect of 4-EG in autoimmune neuroinflammatory disease using the animal model of EAE. We observed that 4-EG treatment ameliorated disease severity and mitigated disease relapse in chronic and relapsing EAE, respectively. In addition, we found 4EG attenuated MG activation, inhibited Th1/Th17 differentiation in the periphery, suppressed Th1/Th17 infiltration of the CNS, and lessened BBB disruption in EAE. Mechanistic studies revealed that the induction of HO-1 might be responsible for the protective effect of 4-EG in EAE. Thus, we show for the first time that 4-EG confers protection against EAE and could be developed as a novel therapeutic agent for the treatment of autoimmune disease EAE.

Pathogenic immune or inflammatory cells are essential for EAE development and progression after infiltrating into the CNS [33]. Here, we found 4-EG suppressed the differentiation of Th1 and Th17 cells in the spleen of EAE, and that might subsequently repress Th1 and Th17 infiltration of the CNS and attenuate neuroinflammation in EAE. Consequently, 4-EG-treated EAE mice exhibited ameliorated disease severity and mitigated EAE pathology compared to vehicle-treated EAE controls. As the suppression of Th1 and Th17 differentiation was observed in the periphery of 4-EG-treated EAE mice, we thought to determine whether 4-EGsuppressed Th1/Th17 differentiation was due to the 

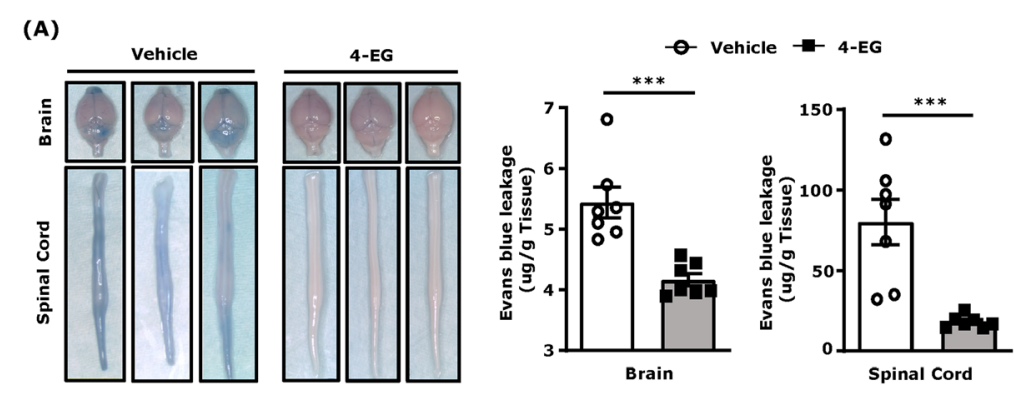

(B)
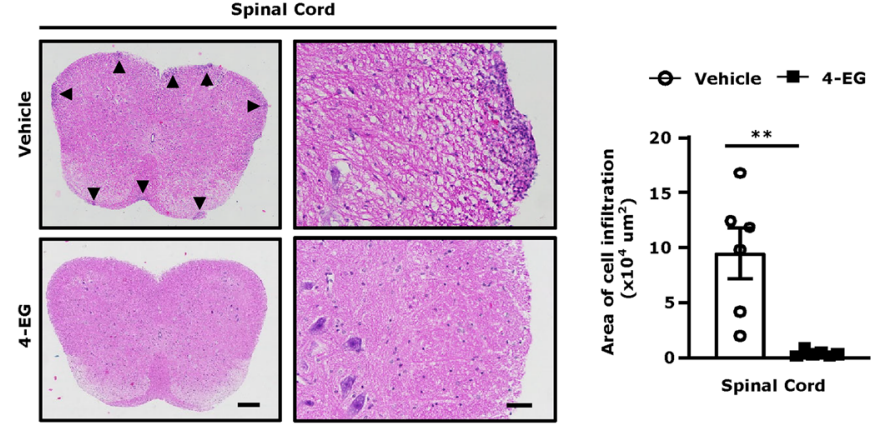

(C)
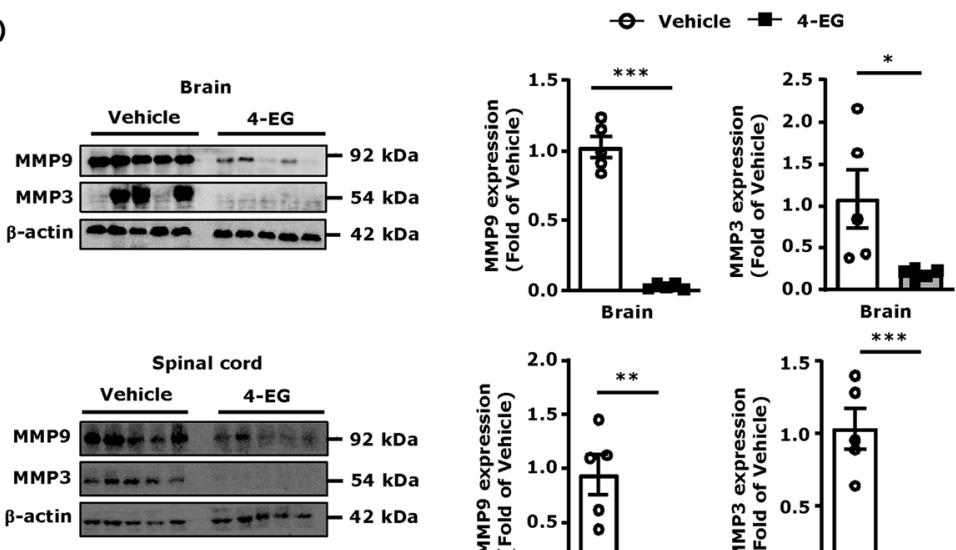

(D)
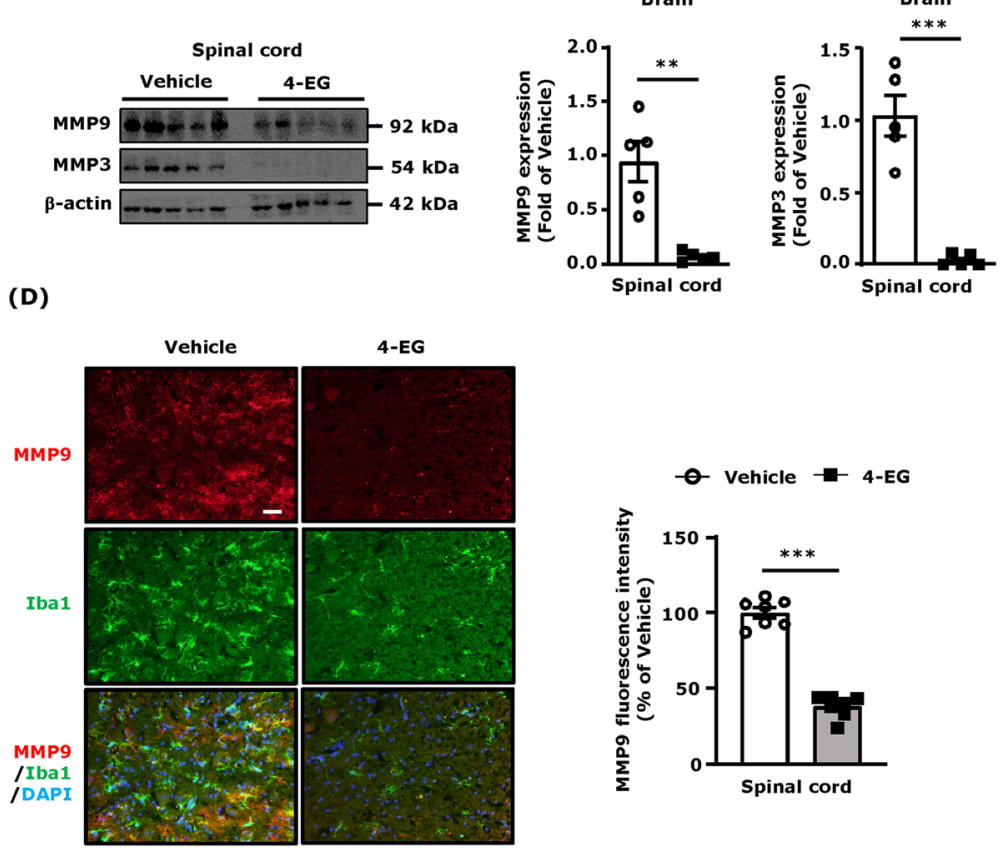

Fig. 5 (See legend on next page.) 
(See figure on previous page.)

Fig. 5 4-EG mitigates BBB disruption, spinal cord pathology, and MMP3/9 expression in EAE. a At day 12-13 post-immunization, vehicle- and 4EG (100 mg/kg)-treated C57BL/6 EAE mice were subjected to i.v. injection of Evans blue. Two hours after Evans blue injection, EAE mice were sacrificed, and the brains and spinal cords were harvested to analyze Evans blue leakage. Representative brain and spinal cord images of three vehicle- and 4-EG-treated EAE are shown, and the amount of Evans blue leakage in the brain and spinal cord tissues was also quantified ( $n=7 /$ group). $\mathbf{b}$ The lumbar regions of the spinal cord harvested from vehicle- and 4-EG-treated C57BL/6 EAE mice were subjected to H\&E staining to determine peripheral immune cell infiltration. Representative H\&E images of the coronal spinal cord sections are shown. Scale bars, $200 \mu \mathrm{m}(\times 10$, left image), $50 \mu \mathrm{m}$ ( $\times 20$, right image). The areas of cell infiltration were quantified ( $n=6 / g r o u p)$. $\mathbf{c}$ The brain and spinal cord tissues were harvested from vehicle- and 4-EG-treated C57BL/6 EAE mice ( $n=5 /$ group) and then subjected to western blot analysis to measure MMP3 and MMP9 expression. Data are representative of two independent experiments ( $n=5 /$ group per experiment). $\mathbf{d}$ The lumbar regions of the spinal cord from vehicle- and 4-EG-treated C57BL/6 EAE mice were subjected to IHC to determine MMP9 and Iba1 expression. Representative images of MMP9 and Iba1 expression are shown. The fluorescence intensity of MMP9 was also quantified ( $n=7 /$ group). Scale bar, $50 \mu m(\times 20)$. Statistical significance was determined as ${ }^{*} p<0.05,{ }^{* *} p<0.01$, and ${ }^{* *} p<0.001$ by unpaired $t$ test

direct effect of 4-EG on the inhibition of pathogenic Th1/Th17 differentiation. We found that in vitro culture of splenocytes under Th1 and Th17 differentiation conditions in the presence of 4-EG inhibited the production of IFN $\gamma$ and IL-17, respectively. These results suggest that 4-EG exerts a direct effect on the suppression of Th1/Th17 differentiation. However, whether 4-EG modulates the production of inflammatory cytokines, such as IL-12 and IL-23, to indirectly suppress Th1 and Th17 differentiation would require further investigations.

MG activation has been reported to be a major modulator in the pathogenesis of autoimmune disorders [34]. Following activation, MG rapidly produce a large amount of pro-inflammatory cytokines and chemokines that promote the recruitment of peripheral immune cells into the CNS, leading to neuroinflammation and subsequent oligodendrocyte death and demyelination in MS/EAE [5]. Because of that, the modulation of MG activation is thought to be a therapeutic strategy for CNS autoimmune diseases. In this study, we demonstrated that 4-EG attenuated MG activation, as we observed the number of $\mathrm{CD} 80^{+}$ and $\mathrm{Iba}^{+} \mathrm{MG}$ was largely decreased in 4-EG-treated EAE mice compared to vehicle-treated EAE controls. In addition, our in vitro studies showed that 4-EG was capable of upregulating phase II detoxification and anti-oxidant enzymes, HO-1, Gclc, and NQO1, in primary MG, and these enzymes have been shown to exert anti-oxidant and anti-inflammatory effects. Altogether, our results suggest that the therapeutic potential of 4-EG in EAE may be in part mediated through its effect on inhibiting MG activation that subsequently attenuates neuroinflammation in EAE.

Recently, it has been shown that GM-CSF plays a pathogenic role in MS [3]. GM-CSF not only exerts an important function in the encephalitogenicity of Th1 and Th17 cells but also promotes proliferation and activation of MG and macrophages, which are essential for the onset of MS/EAE progression [35-37]. Furthermore, GM-CSF can boost the differentiation of M1-like macrophages and induce the production of inflammatory cytokines, such as IL-1 $\beta$, IL-6, and TNF $\alpha$, that may then result in the destruction of myelin sheath $[38,39]$. Moreover, GM-CSF facilitates the inflammasome processing of IL-1 $\beta$ in monocytes and macrophages that further enhances Th17 expansion and BBB disruption [36, 39]. In our study, we found that $\mathrm{CD}_{4}^{+} \mathrm{T}$ cells produced GMCSF in the spleen, brain, and spinal cord of vehicletreated EAE mice that might further aggravate disease progression. In contrast, 4-EG-treated EAE mice exhibited reduced GM-CSF-expressing $\mathrm{CD} 4^{+} \mathrm{T}$ cells in the periphery as well as in the CNS. These results were further confirmed by our in vitro studies in which GMCSF-expressing $\mathrm{CD}^{+} \mathrm{T}$ cells were also decreased in Th1 cultures when 4-EG was present. Collectively, our findings demonstrate that 4-EG possesses an inhibitory effect on the production of GM-CSF in pathogenic T cells in vivo as well as in vitro.

Studies have confirmed that matrix metalloproteinases, especially MMP3 and MMP9, are dysregulated in various diseases, including MS, that result in elevated $\mathrm{BBB}$ disruption and increased leukocyte trafficking $[40,41]$. Consistent with previous studies, we found MMP3 and MMP9 were largely produced in the CNS of EAE mice that correlated with augmented BBB disruption with elevated Evans blue leakage in the CNS. In addition, increased cell infiltrates were observed in the brain and spinal cord of EAE. In contrast, 4-EG treatment was able to suppress MMP3 and MMP9 production, mitigate $\mathrm{BBB}$ disruption, and repress cell infiltrates in the CNS of EAE. These results illustrate the protective effect of 4-EG on maintaining $\mathrm{BBB}$ integrity. Furthermore, previous studies show that GMCSF exerts a detrimental effect on attenuating the expression of tight junction proteins (TJP), claudin- 5 and ZO- 1 , in HBMECs $[33,42]$. As the expression of claudin-5 and ZO-1 is essential for preserving BBB integrity, 4-EG-mediated suppression of GM-CSF may play a role in preventing TJP degradation to preserve BBB's function. However, further studies are required to demonstrate the potential protective effect of 4-EG on attenuating TJP degradation in EAE. 


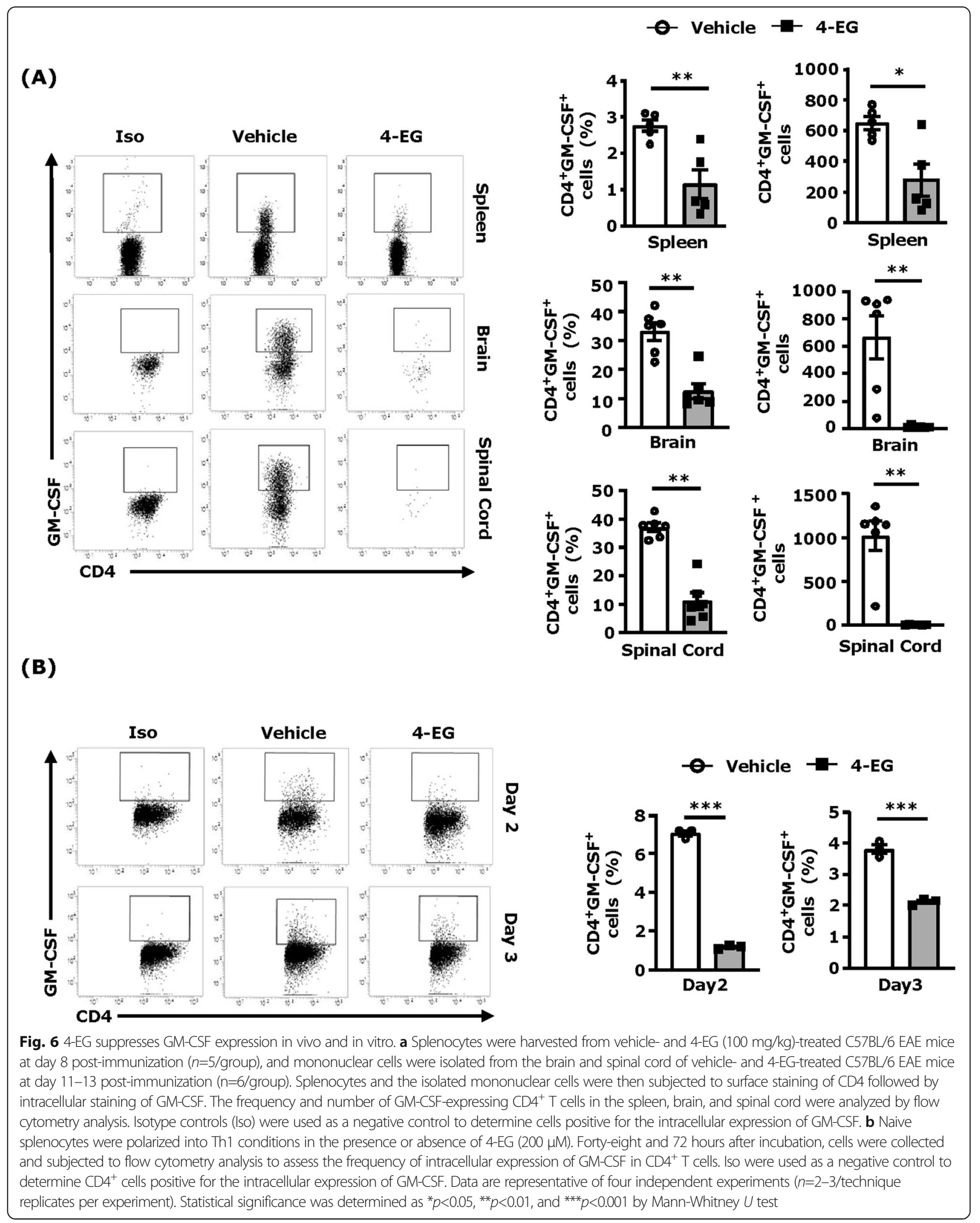




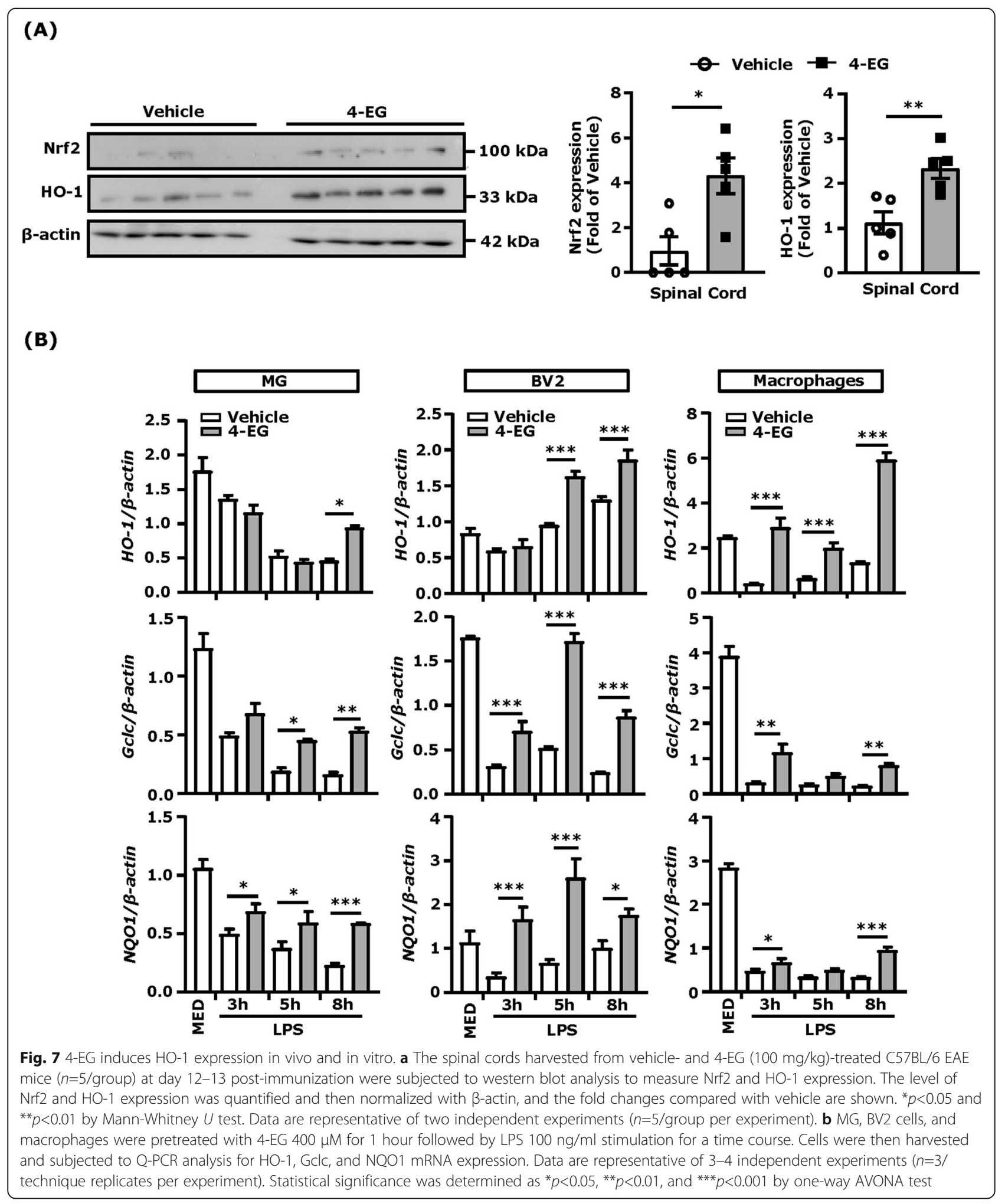

Finally, we investigated the potential molecular mechanism underlying the protective effect of 4-EG in EAE. Previous studies have demonstrated that the induction of $\mathrm{HO}-1$ confers protection against EAE
[29, 43]. For instance, HO-1 inducers, including dimethyl fumarate and 3H-1,2-dithiole-3-thione, have been shown to ameliorate EAE severity $[44,45]$. We found that HO-1 was highly induced in the spinal 
cord of 4-EG-treated EAE mice compared to that of vehicle-treated EAE controls. Since MG and macrophages were reported to express HO-1 [46, 47], we evaluated whether 4-EG promoted HO-1 induction in both MG and macrophages. Indeed, we observed 4EG induced HO-1 upregulation in primary MG, BV2 cells, and primary macrophages in vitro. Taken altogether, our results suggest that the induction of HO-1 by 4-EG in the CNS of EAE may contribute to its protective effect in EAE.

\section{Conclusions}

Our work demonstrated for the first time that 4-EG conferred protection against autoimmune disease EAE. We showed that 4-EG suppressed pathogenic Th1/Th17 differentiation in the periphery and repressed MG activation and Th1/Th17 infiltration in the CNS of EAE. In addition, we observed 4-EG suppressed MMP3 and MMP9 production that might subsequently lessen BBB disruption and repress inflammatory immune cell infiltration of the CNS in EAE. Finally, we demonstrated that 4-EG was capable of inducing HO-1 expression that could offer anti-oxidant and anti-inflammatory effects in EAE. In summary, our study suggests that 4-EG, a natural compound, could be developed into a therapeutic agent for the treatment of MS/EAE through its immunomodulatory effects on the amelioration of disease pathogenesis.

\begin{abstract}
Abbreviations
MS: Multiple sclerosis; CNS: Central nervous system; EAE: Experimental autoimmune encephalomyelitis; MG: Microglia; 4-EG: 4-Ethylguaiacol; BBB: Blood-brain barrier; CFA: Complete Freund's adjuvant; PBS: Phosphatebuffered saline; 7-AAD: 7-Aminoactinomycin D; NQO1: NAD(P)H quinone dehydrogenase 1; Gclc: Glutamate-cysteine ligase catalytic subunit; HO1: Heme oxygenase-1; TJP: Tight junction protein
\end{abstract}

\section{Supplementary Information}

The online version contains supplementary material available at https://doi. org/10.1186/s12974-021-02143-w.

Additional file 1: Table S1. Distribution of tissues from C57BL/6 EAE mice for various experiments.

Additional file 2: Figure S1. Gating strategy of flow cytometry analysis. ( $A$ and $B$ ) Mononuclear cells isolated from the (A) brain and (B) spinal cord of vehicle- and 4-EG-treated C57BL/6 EAE mice were subjected to surface staining of CD4 in the presence of 7-AAD followed by intracellular staining of IFNY, IL-17, or GM-CSF. CD4 ${ }^{+}$cells were gated, and 7-AAD negative live cells were then gated followed by singlet gating. Isotype controls (Iso) were used to determine CD4 ${ }^{+} \mathrm{T}$ cells positive for the intracellular expression of IFNy, IL-17, or GM-CSF. (C) Splenocytes differentiated into Th1 or Th17 conditions were subjected to surface staining of CD4 in the presence of 7-AAD followed by intracellular staining of IFN $\gamma$, IL-17, or GM-CSF. CD4 ${ }^{+} \mathrm{T}$ cells were gated, and 7-AAD negative live cells were then gated followed by singlet gating. Iso were used as a negative control to determine $\mathrm{CD}^{+} \mathrm{T}$ cells positive for the intracellular expression of IFNY, IL-17, or GM-CSF.

Additional file 3: Figure S2. The dose effects of 4-EG in chronic EAE. (A) $\mathrm{C} 57 \mathrm{BL} / 6$ mice were immunized with $\mathrm{MOG}_{35-55}$ and i.p. injected with vehicle or different doses of 4-EG (50, 100, and $200 \mathrm{mg} / \mathrm{kg}, \mathrm{n}=6 / \mathrm{group})$ daily starting from day 3 post-immunization. The clinical score of EAE animals was followed for 30 days. Statistical significance of EAE clinical score was determined as ${ }^{*} p<0.05$ and ${ }^{* *} p<0.001$ by two-way ANOVA test. (B) EAE incidence, mortality, onset of disease, maximum score, and cumulative score were also assessed. Statistical significance was determined as ${ }^{*} p<0.05$ and ${ }^{* * *} p<0.001$ by Mann-Whitney $U$ test.

Additional file 4: Figure S3. The dose effect of 4-EG on Th1 and Th17 cell viability. Naïve splenocytes were polarized into Th1 and Th17 conditions in the presence or absence of different concentrations of 4-EG (200 and $300 \mu \mathrm{M}$ ). After 48 or 72 hours, (A) Th1 and (B) Th17 cells ( $n=3 /$ group/ time point) were collected and subjected to 7-AAD staining to evaluate cell viability by flow cytometery analysis. Statistical significance was determined as ${ }^{*} p<0.05$ and ${ }^{* * *} p<0.001$ by one-way ANOVA test.

\section{Acknowledgements}

Not applicable

\section{Authors' contributions}

WTW performed the experiments, analyzed the data, and wrote the manuscript. PCK performed the experiments and analyzed the data. DAB contributed to the study conception and design, study discussion, and manuscript editing. BAS, DF, and HCP performed the experiments. PYW and ICY contributed to the study discussion and manuscript editing. JHY conceived the study, designed the experiments, and wrote the manuscript. All authors read and approved the final manuscript.

Funding

This work was supported by Anna Yoder MS Fund to J-H. Yen.

Availability of data and materials

The datasets of the current study are available from the corresponding author on a reasonable request.

\section{Declarations}

\section{Ethics approval and consent to participate}

All applicable international, national, and/or institutional guidelines for the care and use of animals were followed. This study does not contain any experiments with human participants performed by any of the authors.

\section{Consent for publication}

Not applicable.

\section{Competing interests}

The authors declare that they have no competing interests.

\section{Author details}

${ }^{1}$ Department of Microbiology and Immunology, Indiana University School of Medicine, 2101 E. Coliseum Boulevard, Fort Wayne, IN 46805, USA.

${ }^{2}$ Department of Pharmaceutical Sciences, Manchester University College of Pharmacy, Natural and Health Sciences, Fort Wayne, IN, USA. ${ }^{3}$ Department of Anatomy, Cell Biology and Physiology, Indiana University School of Medicine, Fort Wayne, IN, USA. ${ }^{4}$ Graduate Institute of Brain and Mind Science, College of Medicine, National Taiwan University, Taipei, Taiwan.

Received: 16 October 2020 Accepted: 29 March 2021

Published online: 11 May 2021

\section{References}

1. Correale J, Gaitán MI, Ysrraelit MC, Fiol MP. Progressive multiple sclerosis: from pathogenic mechanisms to treatment. Brain. 2017;140(3):527-46. https://doi.org/10.1093/brain/aww258.

2. Oh J, Vidal-Jordana A, Montalban X. Multiple sclerosis: clinical aspects. Curr Opin Neurol. 2018;31(6):752-9. https://doi.org/10.1097/WCO. 0000000000000622 .

3. Rasouli J, Ciric B, Imitola J, Gonnella P, Hwang D, Mahajan K, et al. Expression of GM-CSF in T cells is increased in multiple sclerosis and suppressed by IFN- $\beta$ therapy. J Immunol. 2015;194(11):5085-93. https://doi. org/10.4049/jimmunol.1403243. 
4. Willing A, Jäger J, Reinhardt S, Kursawe N, Friese MA. Production of IL-17 by MAIT cells is increased in multiple sclerosis and is associated with IL-7 receptor expression. J Immunol. 2018;200(3):974-82. https://doi.org/10.4049/ jimmunol.1701213.

5. Zhou J, Cai W, Jin M, Xu J, Wang Y, Xiao Y, et al. 18ß-Glycyrrhetinic acid suppresses experimental autoimmune encephalomyelitis through inhibition of microglia activation and promotion of remyelination. Sci Rep. 2015;5(1): 13713. https://doi.org/10.1038/srep13713.

6. Graf BA, Milbury PE, Blumberg JB. Flavonols, flavones, flavanones, and human health: epidemiological evidence. J Med Food. 2005;8(3):281-90. https://doi.org/10.1089/jmf.2005.8.281.

7. Arts IC, Hollman PC. Polyphenols and disease risk in epidemiologic studies. Am J Clin Nutr. 2005;81(1 Suppl):317S-25S. https://doi.org/10.1093/ajcn/ 81.1.317S.

8. Zhao DR, Jiang YS, Sun JY, Li HH, Luo XL, Zhao MM. Anti-inflammatory mechanism involved in 4-ethylguaiacol-mediated inhibition of LPS-induced inflammation in THP-1 cells. J Agric Food Chem. 2019;67(4):1230-43. https:// doi.org/10.1021/acs.jafc.8b06263.

9. Caboni P, Sarais G, Cabras M, Angioni A. Determination of 4-ethylphenol and 4-ethylguaiacol in wines by LC-MS-MS and HPLC-DAD-fluorescence. J Agric Food Chem. 2007;55(18):7288-93. https://doi.org/10.1021/jf071156m.

10. Steensels J, Daenen L, Malcorps P, Derdelinckx G, Verachtert H, Verstrepen KJ. Brettanomyces yeasts--from spoilage organisms to valuable contributors to industrial fermentations. Int J Food Microbiol. 2015;206:24-38. https://doi. org/10.1016/j.ijfoodmicro.2015.04.005.

11. Zhao D, Jiang Y, Sun J, Li H, Huang M, Sun X, et al. Elucidation of the antiinflammatory effect of vanillin in Lps-activated THP-1 cells. J Food Sci. 2019; 84(7):1920-8. https://doi.org/10.1111/1750-3841.14693.

12. Nguyen T, Nioi P, Pickett CB. The Nrf2-antioxidant response element signaling pathway and its activation by oxidative stress. J Biol Chem. 2009; 284(20):13291-5. https://doi.org/10.1074/jbc.R900010200.

13. Itoh K, Mochizuki M, Ishii Y, Ishii T, Shibata T, Kawamoto $Y$, et al. Transcription factor Nrf2 regulates inflammation by mediating the effect of 15-deoxy- $\Delta^{12,14}$-prostaglandin J2. Mol Cell Biol. 2004;24(1):36-45. https://doi. org/10.1128/MCB.24.1.36-45.2004.

14. Kuo PC, Weng WT, Scofield BA, Paraiso HC, Brown DA, Wang PY, et al. Dimethyl itaconate, an itaconate derivative, exhibits immunomodulatory effects on neuroinflammation in experimental autoimmune encephalomyelitis. J Neuroinflammation. 2020;17(1):138. https://doi.org/1 0.1186/s12974-020-01768-7.

15. Kuo PC, Brown DA, Scofield BA, Paraiso HC, Wang PY, Yu IC, et al. Dithiolethione ACDT suppresses neuroinflammation and ameliorates disease severity in experimental autoimmune encephalomyelitis. Brain Behav Immun. 2018;70:76-87. https://doi.org/10.1016/j.bbi.2018.03.010.

16. Song $\mathrm{CH}$, Kim N, Kim DH, Lee HN, Surh YJ. 17- $\beta$ estradiol exerts antiinflammatory effects through activation of $\mathrm{Nrf} 2$ in mouse embryonic fibroblasts. PLoS One. 2019;14(8):e0221650. https://doi.org/10.1371/journal. pone.0221650

17. Jaramillo MC, Zhang DD. The emerging role of the Nrf2-Keap1 signaling pathway in cancer. Genes Dev. 2013;27(20):2179-91. https://doi.org/10.1101/ gad.225680.113.

18. Zhang DD. Mechanistic studies of the Nrf2-Keap1 signaling pathway. Drug Metab Rev. 2006:38(4):769-89. https://doi.org/10.1080/03602530600971974.

19. Kreutzberg GW. Microglia: a sensor for pathological events in the CNS. Trends Neurosci. 1996;19(8):312-8. https://doi.org/10.1016/0166-2236(96)10049-7.

20. Kuo PC, Weng WT, Scofield BA, Furnas D, Paraiso HC, Intriago AJ, et al. Interferon- $\beta$ alleviates delayed tPA-induced adverse effects via modulation of MMP3/9 production in ischemic stroke. Blood Adv. 2020;4(18):4366-81. https://doi.org/10.1182/bloodadvances.2020001443.

21. Hooper KM, Yen JH, Kong W, Rahbari KM, Kuo PC, Gamero AM, et al. Prostaglandin E2 inhibition of IL-27 production in murine dendritic cells: a novel mechanism that involves IRF1. J Immunol. 2017;19(4):1521-30. https:// doi.org/10.4049/jimmunol.1601073.

22. Greter M, Lelios I, Croxford AL. Microglia versus myeloid cell nomenclature during brain inflammation. Front Immunol. 2015;6:249.

23. Aloisi F. Immune function of microglia. Glia. 2001;36(2):165-79. https://doi. org/10.1002/glia.1106.

24. Gelderblom M, Leypoldt F, Steinbach K, Behrens D, Choe CU, Siler DA, et al. Temporal and spatial dynamics of cerebral immune cell accumulation in stroke. Stroke. 2009:40(5):1849-57. https://doi.org/10.1161/STROKEAHA.108. 534503
25. Balasa R, Barcutean L, Balasa A, Motataianu A, Roman-Filip C, Manu D. The action of TH17 cells on blood brain barrier in multiple sclerosis and experimental autoimmune encephalomyelitis. Hum Immunol. 2020;81(5): 237-43. https://doi.org/10.1016/j.humimm.2020.02.009

26. Katsnelson A, De Strooper B, Zoghbi HY. Neurodegeneration: from cellular concepts to clinical applications. Sci Transl Med. 2016;8(364):364ps18.

27. Sato W. Chemokine receptor expression of T cells in the cerebrospinal fluid of relapsing multiple sclerosis. Nihon Rinsho Meneki Gakkai Kaishi. 2014; 37(2):83-9. https://doi.org/10.2177/jsci.37.83.

28. Griffin, J.D., Cannistra S.A., Demetri G.D., Ernst T.J., Kanakura Y., Sullivan R., The biology of GM-CSF: regulation of production and interaction with its receptor. Int J Cell Cloning, 1990. 8 Suppl 1: p. 35-44; discussion 44-5, DOI: https://doi.org/10.1002/stem.5530080705.

29. Liu Y, Zhu B, Luo L, Li P, Paty DW, Cynader MS. Heme oxygenase-1 plays an important protective role in experimental autoimmune encephalomyelitis. Neuroreport. 2001;12(9):1841-5. https://doi.org/10.1097/00001756-20010703 0-00016.

30. Chen SJ, Wang YL, Lo WT, Wu CC, Hsieh CW, Huang CF, et al. Erythropoietin enhances endogenous haem oxygenase- 1 and represses immune responses to ameliorate experimental autoimmune encephalomyelitis. Clin Exp Immunol. 2010;162(2):210-23. https://doi.org/10.1111/j.1365-2249.2010.04238.x.

31. Hauptmann J, Johann L, Marini F, Kitic M, Colombo E, Mufazalov IA, et al. Interleukin-1 promotes autoimmune neuroinflammation by suppressing endothelial heme oxygenase-1 at the blood-brain barrier. Acta Neuropathol. 2020;140(4):549-67. https://doi.org/10.1007/s00401-020-02187-x.

32. Keum, Y.S., Regulation of Nrf2-mediated phase II detoxification and antioxidant genes. Biomol Ther (Seoul), 2012. 20(2): p. 144-151, 2, DOl: https:// doi.org/10.4062/biomolther.2012.20.2.144

33. Kempuraj $D$, et al. Neuroinflammation induces neurodegeneration. J Neurol Neurosurg Spine. 2016;(1):1003.

34. Choi BY, Kim JH, Kho AR, Kim IY, Lee SH, Lee BE, et al. Inhibition of NADPH oxidase activation reduces EAE-induced white matter damage in mice. J Neuroinflammation. 2015;12(1):104. https://doi.org/10.1186/s12 974-015-0325-5.

35. Croxford AL, Spath S, Becher B. GM-CSF in neuroinflammation: licensing myeloid cells for tissue damage. Trends Immunol. 2015:36(10):651-62. https://doi.org/10.1016/j.it.2015.08.004.

36. Ifergan I, Davidson TS, Kebir H, Xu D, Palacios-Macapagal D, Cann J, et al. Targeting the GM-CSF receptor for the treatment of CNS autoimmunity. J Autoimmun. 2017:84:1-11. https://doi.org/10.1016/j.jaut.2017.06.005.

37. Duncker PC, Stoolman JS, Huber AK, Segal BM. GM-CSF promotes chronic disability in experimental autoimmune encephalomyelitis by altering the composition of central nervous system-infiltrating cells, but is dispensable for disease induction. J Immunol. 2018;200(3):966-73. https://doi.org/10.404 9/jimmunol.1701484.

38. Wahi K, Kodar K, McConnell MJ, Harper JL, Timmer MSM, Stocker BL. MSU crystals enhance TDB-mediated inflammatory macrophage IL-1 $\beta$ secretion. Inflammation. 2019;42(3):1129-36. https://doi.org/10.1007/s1 0753-019-00976-5.

39. Komuczki, J., et al., Fate-mapping of GM-CSF expression identifies a discrete subset of inflammation-driving $T$ helper cells regulated by cytokines IL-23 and IL-1ß. Immunity, 2019; 50(5): p. 1289-1304.e6.

40. Gerwien $\mathrm{H}$, et al. Imaging matrix metalloproteinase activity in multiple sclerosis as a specific marker of leukocyte penetration of the blood-brain barrier. Sci Transl Med. 2016:8:364ra152.

41. Mirshafiey A, Asghari B, Ghalamfarsa G, Jadidi-Niaragh F, Azizi G. The significance of matrix metalloproteinases in the immunopathogenesis and treatment of multiple sclerosis. Sultan Qaboos Univ Med J. 2014;14(1):e1325. https://doi.org/10.12816/0003332.

42. Borjini N, Fernández M, Giardino L, Calzà L. Cytokine and chemokine alterations in tissue, CSF, and plasma in early presymptomatic phase of experimental allergic encephalomyelitis (EAE), in a rat model of multiple sclerosis. J Neuroinflammation. 2016;13(1):291. https://doi.org/10.1186/s12 974-016-0757-6.

43. Chora AA, Fontoura P, Cunha A, Pais TF, Cardoso S, Ho PP, et al. Heme oxygenase- 1 and carbon monoxide suppress autoimmune neuroinflammation. J Clin Invest. 2007;117(2):438-47. https://doi.org/10.11 $72 / \mathrm{JCl} 28844$.

44. Kasarello K, et al. Effect of dimethyl fumarate on heme oxygenase-1 expression in experimental allergic encephalomyelitis in rats. Folia Neuropathol. 2017;55(4):325-32. https://doi.org/10.5114/fn.2017.72394. 
45. Kuo PC, Brown DA, Scofield BA, Yu IC, Chang FL, Wang PY, et al. 3H-1,2dithiole-3-thione as a novel therapeutic agent for the treatment of experimental autoimmune encephalomyelitis. Brain Behav Immun. 2016;57: 173-86. https://doi.org/10.1016/j.bbi.2016.03.015.

46. Lin W, Chen W, Liu K, Ma P, Qiu P, Zheng C, et al. Mitigation of microgliamediated acute neuroinflammation and tissue damage by heme oxygenase 1 in a rat spinal cord injury model. Neuroscience. 2021;457:27-40. https:// doi.org/10.1016/..neuroscience.2020.08.001.

47. Ko W, et al. Neuroprotective and anti-inflammatory effects of Kuwanon C from Cudrania tricuspidata are mediated by heme oxygenase- 1 in HT22 hippocampal cells, RAW264.7 macrophage, and BV2 microglia. Int J Mol Sci. 2020;21(14):4839.

\section{Publisher's Note}

Springer Nature remains neutral with regard to jurisdictional claims in published maps and institutional affiliations.

- fast, convenient online submission

- thorough peer review by experienced researchers in your field

- rapid publication on acceptance

- support for research data, including large and complex data types

- gold Open Access which fosters wider collaboration and increased citations

- maximum visibility for your research: over $100 \mathrm{M}$ website views per year

At $\mathrm{BMC}$, research is always in progress. 